\title{
O PAPEL DAS CORPORAÇÕES TRANSNACIONAIS NO DIREITO HUMANO À ALIMENTAÇÃO
}

\author{
THE ROLE OF TRANSNATIONAL CORPORATIONS IN THE HUMAN RIGHT TO
}

FOOD

\author{
EL PAPEL DE LAS CORPORATIVAS TRANSNACIONALES EN EL DERECHO \\ HUMANO A LA ALIMENTACIÓN
}

\begin{abstract}
ISADORA KAUANA LAZARETTI
Mestranda em Direito pela Universidade Comunitária da Região de Chapecó (Unochapecó). Bolsista na modalidade bolsa de apoio à produção científica financiada pela Unochapecó. Chapecó, Santa Catarina, Brasil. http:/ / lattes.cnpq.br/4070049769045027 / http://orcid.org/0000-0002-6916-5749 /

isadoralazaretti@unochapeco.edu.br
\end{abstract}

GIOVANNI OLSSON Doutor em Direito pela Universidade Federal de Santa Catarina (UFSC). Pesquisador do Grupo de Pesquisa Relações Internacionais, Direito e Poder (CNPQ). Professor Permanente do Programa de Mestrado em Direito na Universidade

Comunitária Regional Unochapecó). Chapecó, Santa Catarina, Brasil. http://lattes.cnpq.br/1890264911560158 / http://orcid.org/0000-0003-2602-1320 / golsson71@gmail.com

\begin{abstract}
RESUMO
O presente artigo tem como objetivo analisar a atuação das corporações transnacionais e seus reflexos no direito humano à alimentação. As corporações transnacionais são atores internacionais não estatais que exercem significativo protagonismo na arena internacional pelo seu poder de barganha e influência. A finalidade primordial desses atores é a maximização do lucro, e sua atuação reflete diretamente no direito humano à alimentação. Atualmente, existe um sistema alimentício mundial estruturado apenas para a geração de lucros em favor das corporações transnacionais, que opera tanto na prevalência da conversão de alimentos humanos básicos em ração animal, como também na utilização de agrotóxicos e transgênicos nos alimentos comercializados. Essas situações ajudam a explicar por que o direito humano à alimentação não é absolutamente efetivado. A metodologia utilizada neste artigo consiste no método dedutivo e a pesquisa é de caráter qualitativo. A técnica de pesquisa utilizada foi a bibliográfica.
\end{abstract}

Palavras-chave: Atores internacionais; Corporações transnacionais; Direitos Humanos.

\begin{abstract}
This article aims to analyze the performance of transnational corporations and their impact on the human right to food. Transnational corporations are non-state international actors that play a significant role in the international arena because of their bargaining power and influence. The primary purpose of these actors is to maximize profit, and their performance directly reflects on the human right to food. Currently, there is a global food system structured only for the generation of profits in favor of transnational corporations, which operates both in the prevalence of conversion of basic human food to animal feed, as well as in the use of pesticides and transgenics in commercialized foods. These situations help explain why the human right to food is not absolutely made effective. The methodology used in this article consists in the deductive method and qualitative research. The research technique used was the bibliographical one.
\end{abstract}

Keywords: International actors; International corporations; Human Rigths. 


\section{RESUMEN}

El presente artículo tiene como objetivo analizar la actuación de las corporaciones transnacionales y sus reflejos en el derecho humano a la alimentación. Las corporaciones transnacionales son actores internacionales no estatales que ejercen significativo protagonismo en la arena internacional por su poder de negociación e influencia. La finalidad primordial de estos actores es la maximización del beneficio, y su actuación refleja directamente en el derecho humano a la alimentación. Actualmente, existe un sistema alimentario mundial estructurado sólo para la generación de beneficios a favor de las corporaciones transnacionales, que opera tanto en la prevalencia de la conversión de alimentos humanos básicos en ración animal, así como en la utilización de agrotóxicos y transgénicos en los alimentos comercializados. Estas situaciones ayudan a explicar por qué el derecho humano a la alimentación no es absolutamente efectivo. La metodología utilizada en este artículo consiste en el método deductivo y la investigación es de carácter cualitativo. La técnica de investigación utilizada fue la bibliográfica.

Palabras clave: Actores internacionales; Corporaciones transnacionales; Derechos Humanos.

\section{SUMÁRIO}

INTRODUÇÃO; 1 OS DIREITOS HUMANOS E A ALIMENTAÇÃO; 2 AS CORPORAÇÕES TRANSNACIONAIS COMO ATORES NO CENÁRIO INTERNACIONAL; 3 O PAPEL DAS CORPORAÇÕES TRANSNACIONAIS NA (IN)EFETIVIDADE DO DIREITO HUMANO À ALIMENTAÇÃO; CONCLUSÃO; REFERÊNCIAS.

\section{INTRODUÇÃO}

0 presente artigo versa sobre o papel das corporações transnacionais no cenário internacional e seus reflexos no direito humano da alimentação. As corporações transnacionais são atores internacionais de natureza não estatal que exercem significativo protagonismo na arena internacional em razão de seu poder de barganha e influência perante os demais atores que fazem parte da sociedade internacional contemporânea.

O objetivo geral deste artigo consiste em analisar o papel das corporações transnacionais no direito humano da alimentação. Especificamente, objetiva-se estudar os direitos humanos e seus desafios; compreender a noção de ator internacional, com ênfase nas corporações transnacionais junto à sociedade internacional contemporânea; e, por fim, analisar o papel das corporações transnacionais na efetividade do direito humano da alimentação.

$\mathrm{Na}$ medida em que a finalidade primordial das corporações transnacionais é a maximização do lucro, estas possuem propósitos eminentemente econômicos. Essa atuação desmedida e ilimitada está refletindo diretamente no direito humano da alimentação. Atualmente, prevalece um sistema industrial-alimentício estruturado e projetado para gerar lucros às corporações transnacionais, inclusive a aquelas que atuam no fornecimento de produtos químicos extremamente nocivos à saúde humana e incorporados na cadeia produtiva.

O direito de alimentar-se constitui um direito humano que decorre do direito à vida, considerado o bem mais importante protegido pela ordem jurídica internacional no que se refere 
à pessoa humana. 0 direito à alimentação abrange não somente a garantia do acesso diário a alimentos, mas assegura uma alimentação balanceada, saudável e de qualidade. Deste modo, considerando que a dignidade da pessoa humana é o principal fundamento da Declaração Universal dos Direitos Humanos, e que a alimentação constitui uma necessidade à sobrevivência humana, o estudo da efetividade desse direito mostra-se imprescindível no atual cenário.

Ademais, faz-se necessário ainda compreender e delimitar a atuação das corporações transnacionais na sociedade internacional e como sua atuação reflete na vida do ser humano ao ponto de ameaçar direitos básicos inerentes à condição de pessoa humana. Trata-se, portanto, de uma temática complexa, contemporânea e instigante.

Utilizando-se do método dedutivo e adotando a técnica de pesquisa bibliográfica, a dinâmica de análise do presente estudo ocupa-se com a realidade e a atuação das corporações transnacionais e seus reflexos no direito humano da alimentação.

\section{OS DIREITOS HUMANOS E A ALIMENTAÇÃO}

O surgimento dos direitos humanos está diretamente inserido em um contexto histórico determinado, marcado por inúmeros conflitos internacionais entre Estados. Registram-se períodos históricos de intensas lutas e embates que resultaram em conquistas e vitórias e que fizeram com que os direitos humanos fossem evoluindo cada vez mais. Os direitos humanos surgiram de modo gradual, não todos de uma vez e tampouco de uma vez por todas. Nascem no momento em que se verifica um aumento de poder do homem de dominar a natureza e os próprios homens a sua volta, fazendo com que as liberdades individuais passassem a estar ameaçadas ${ }^{1}$.

Em tempos mais remotos, inúmeros foram os momentos marcados pelas mais graves violações de direitos humanos, quando a diversidade era desculpa para dizimar direitos. A percepção de diferenças em um indivíduo perpassava a ideia de seres indignos, descartáveis ou supérfluos. A escravidão, os campos de extermínio, o racismo, a homofobia e a xenofobia constituem exemplos das horrendas violações de direitos humanos que marcaram a história da humanidade ${ }^{2}$.

\footnotetext{
${ }^{1}$ BOBBIO, Norberto. A era dos direitos. Rio de Janeiro: Campus, 1992. p. 5-6.

${ }^{2}$ PIOVESAN, Flávia. Temas de direitos humanos. 5. ed. São Paulo: Saraiva, 2012. p. 48.
} 
A Primeira e a Segunda Guerras Mundiais constituem importantes fatos históricos que contribuíram consideravelmente para que se passasse a dispensar maior atenção aos direitos humanos. $\mathrm{Na}$ busca da criação de novas garantias, em razão das atrocidades vivenciadas, sentiuse uma necessidade cada vez mais intensa de mecanismos que pudessem proteger a humanidade.

Assim, sobrevém a Declaração Universal dos Direitos do Homem, em 1948, uma das mais importantes conquistas da história dos direitos humanos. Pela primeira vez na formação desses direitos, a Declaração Universal mostra-se um fato inédito em que um sistema de princípios fundamentais da conduta do ser humano foi expressa e livremente aceito. A Declaração Universal dos Direitos do Homem apresenta-se como uma manifestação da única prova da qual um sistema de valores pode ser considerado humanamente fundado e devidamente reconhecido. Ela foi acolhida como o consenso geral do fundamento do direito, reconhecida como inspiração e orientação no processo de crescimento e desenvolvimento de toda a comunidade internacional ${ }^{3}$.

Partindo para sua categorização conceitual, os direitos humanos originaram-se como um conjunto de faculdades e instituições que materializam a dignidade, a liberdade e a igualdade a cada contexto histórico. Tais direitos devem ser reconhecidos positivamente pelos ordenamentos jurídicos, tanto no que tange à ordem jurídica interna dos Estados, como no plano internacional ${ }^{4}$.

Os direitos humanos estabelecem-se como um instrumento de garantia da dignidade humana e, por isso, devem ser estudados e levados à prática. Esses estudos devem ser realizados "apoiados em um saber crítico que desvele as eleições e os conflitos de interesse que se escondem atrás de todo o debate repleto de ideologias", além de serem inseridos em todos os contextos do mundo da vida (social, cultural, político, etc.), onde os direitos necessariamente surgem e se transformam ${ }^{5}$.

Todavia, o caráter natural, universal e igualitário atribuído aos direitos humanos por si só não se torna suficiente. A eficácia dos direitos humanos só é expressiva quando estes recebem conteúdo político, ou seja, "não são os direitos de humanos num estado de natureza: são os direitos de humanos em sociedade". Isso significa que os direitos humanos devem ser garantidos

\footnotetext{
${ }^{3}$ BOBBIO, Norberto. A era dos direitos. Rio de Janeiro: Campus, 1992. p. 26-30.

${ }^{4}$ PÉREZ LUÑO, Antonio Enrique. Derechos humanos, estado de derecho y constitución. 4. ed. Madrid: Tecnos, 1991. p. 48.

${ }^{5}$ PRONER, Carol. Os direitos humanos e seus paradoxos: análise do sistema americano de proteção. Porto Alegre: Sergio Antonio Fabris, 2002. p. 40.
} 
no "mundo político secular", e esses direitos exigem a participação ativa do Estado enquanto ente capaz de garanti-los ${ }^{6}$.

Não se trata de categorias normativas que existem no mundo contemporâneo de forma imutável, esperando para serem colocadas em prática através de ações sociais. Os direitos humanos estão em constante criação e transformação". Johann Galtung considera que "a abordagem dos diretos humanos é uma abordagem de contrato social, sendo o contrato entre os

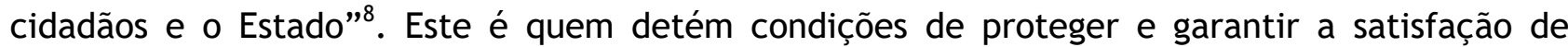
necessidades de bem-estar da população a partir do uso do seu poder consolidado no weberiano monopólio da violência legítima.

Partindo do pressuposto de que os direitos humanos fundam-se no princípio da dignidade da pessoa humana, faz-se necessário analisar a relação entre as necessidades humanas e os direitos humanos. Nesse sentido, cabe destacar a circunstância fundamental e óbvia, mas usualmente ignorada, de que as necessidades humanas estão localizadas dentro dos seres humanos, enquanto que os direitos humanos estão localizados entre estes seres humanos. A necessidade humana é inerente ao indivíduo, e é este que a sente. A título exemplificativo, na medida em que o ser humano sente fome, o agente de satisfação dessa necessidade humana são os alimentos. Com isso, adotando a concepção estudada por Johann Galtung, o indivíduo "é um sujeito de necessidades". Deste modo, e na mesma linha, para que o indivíduo possa satisfazer as necessidades humanas, como, por exemplo, a alimentação, é imprescindível a existência de um elemento material, isto é, uma economia material de satisfação de necessidades dessa natureza?.

Por isso, o estudo dos direitos humanos está relacionado com as necessidades humanas que dizem respeito basicamente à sobrevivência e à liberdade. Não existem apenas essas necessidades das quais os direitos humanos estão vinculados, mas se pode dizer que estas são as necessidades mais ameaçadas. Nesse sentido, Galtung considera que "a satisfação das necessidades depende das inclinações e das ações de um número relativamente limitado de

\footnotetext{
${ }^{6}$ HUNT, Lynn. A invenção dos direitos humanos: uma história. Tradução de Rosaura Eichenberg. São Paulo: Companhia das Letras, 2009. p. 19.

7 PRONER, Carol. Os direitos humanos e seus paradoxos: análise do sistema americano de proteção. Porto Alegre: Sergio Antonio Fabris, 2002. p. 41.

${ }^{8}$ GALTUNG, Johan. Direitos humanos: uma nova perspectiva. Tradução de Margarida Fernandes. Lisboa: Instituto Piaget, 1994. p. 104.

${ }^{9}$ Ibidem. p. 91-93.
} 
atores particulares". Para ele, "os direitos são os meios e a satisfação de necessidades são o fim"10.

Dentre os direitos inseridos no contexto das necessidades humanas, papel fundamental é dado ao direito humano à alimentação, "por envolver tanto instâncias internacionais de cooperação em termos de recursos naturais e tecnológicos como a responsabilidade individual de prover meios para seu próprio desenvolvimento"11.

Partindo de tal concepção, o desenvolvimento jurídico do direito humano à alimentação tem se apresentado em contínua progressão. A defesa e proteção desse direito, assim como sua positivação em instrumentos normativos internacionais e nacionais, constitui uma medida adotada como resposta a uma das maiores crises humanitárias que assolam a humanidade - a fome -, problema social que infelizmente ainda é uma trágica realidade no cotidiano mundial.

Inicialmente, o direito humano à alimentação era compreendido a partir de disposições que tratavam do direito com base num "adequado nível de vida". Posteriormente, e em decorrência dos próprios avanços legislativos, o direito à alimentação passou a ser aplicado a uma série de situações, como uma garantia fundamental da pessoa humana, relacionado especialmente ao direito à vida, ao desenvolvimento e à saúde ${ }^{12}$.

O Estado é o principal responsável pela proteção dos direitos econômicos, sociais e culturais, nos quais se insere o direito à alimentação. É seu dever adotar medidas que proporcionem o protagonismo individual e a supervisão internacional desse direito, como a implementação de políticas públicas eficazes de combate à fome e à miséria, e, além disso, garantir uma alimentação adequada e de qualidade.

$\mathrm{O}$ direito humano à alimentação pode ser regulado por uma série de normas imperativas que visam à satisfação dessa necessidade humana básica que se relaciona com a sua própria sobrevivência, com o bem-estar, com a liberdade e com a identidade do ser humano ${ }^{13}$, das quais toda pessoa necessita de um padrão mínimo ao longo de sua existência. A sobrevivência, por óbvio, é suportada individualmente, e um dos principais fatores necessários à garantia da sobrevivência é exatamente a alimentação.

\footnotetext{
${ }^{10}$ GALTUNG, Johan. Direitos humanos: uma nova perspectiva. Tradução de Margarida Fernandes. Lisboa: Instituto Piaget, 1994. p.108-109.

${ }^{11}$ VALENTE, Flavio Luiz Schieck. Introdução. In: VALENTE, Flavio Luiz Schieck (Org.). Direito humano à alimentação: desafios e conquistas. São Paulo: Cortez, 2002. p. 18.

${ }^{12}$ Ibidem.

${ }^{13}$ GALTUNG, Johan. Direitos humanos: uma nova perspectiva. Tradução de Margarida Fernandes. Lisboa: Instituto Piaget, 1994. p. 109.
} 
Assegurar ao indivíduo uma alimentação adequada é garantir-lhe um direito humano básico, uma vez que, sem a garantia dessa, tanto do ponto de vista de quantidade e qualidade, não se pode falar em efetivação do direito à vida. Nesse viés, o direito à alimentação manifestase pela luta contra a fome, buscando assegurar que todo ser humano tenha acesso diário a alimentos suficientes para atender suas necessidades vitais básicas fundamentais para a manutenção da saúde e da sua integridade física e psicológica ${ }^{14}$.

Por fim, tem-se que a alimentação constitui uma necessidade essencial à sobrevivência humana, e, em face desse caráter de essencialidade, é protegida como um direito humano cujo principal fundamento é a garantia da dignidade da pessoa humana uma vez que primacialmente se relaciona com o direito à vida, à saúde e ao desenvolvimento. Assim, estudados os direitos humanos e seus desafios com ênfase no direito à alimentação, passa-se ao estudo dos atores internacionais no cenário internacional e como sua atuação interfere nessa questão.

\section{AS CORPORAÇÕES TRANSNACIONAIS COMO ATORES NO CENÁRIO INTERNACIONAL}

A sociedade internacional sempre esteve, até então, marcada pelo protagonismo dos Estados soberanos, definida, assim, como uma sociedade tipicamente interestatal. No decorrer da segunda metade do século XX, a sociedade internacional passou a informar novos parâmetros em função do surgimento e do papel exercido pelos novos atores internacionais ${ }^{15}$. A mudança da posição estatocêntrica do Estado decorreu da própria evolução dinâmica da sociedade, seja no aspecto interno, seja no aspecto internacional. A principal causa dessas mudanças decorre do surgimento dos atores não estatais transnacionais, assim como da expansão e intensificação do mercado globalizado, fazendo com que a capacidade absoluta dos Estados restasse limitada ${ }^{16}$.

Esses aspectos foram determinantes para que o protagonismo dos novos atores internacionais ocupasse espaço considerável no cenário internacional, influenciando, inclusive, a

\footnotetext{
${ }^{14}$ VALENTE, Flavio Luiz Schieck. Do combate à fome à segurança alimentar e nutricional: o direito à alimentação adequada. In: VALENTE, Flavio Luiz Schieck. (Org.). Direito humano à alimentação: desafios e conquistas. São Paulo: Cortez, 2002. p. 37.

${ }^{15}$ BEDIN, Gilmar Antônio. A sociedade internacional e o século XXI: em busca da construção de uma ordem judicial justa e solidária. Ijuí: Unijuí, 2001. p. 268.

${ }^{16}$ OLIVEIRA, Odete Maria de. Relações internacionais, direito e atores não estatais: delineamentos de fundamentação. In: OLIVEIRA, Odete Maria de. (Org.). Relações internacionais, direito e poder: cenários e protagonismos dos atores não estatais. Vol. I. Ijuí: Unijuí, 2014. p. 33.
} 
autoridade estatal. Com isso, gerou-se uma nova configuração das relações internacionais, aumentando a complexidade das relações, estabelecendo uma polaridade incerta e acentuando os vínculos de interdependência. Em linhas gerais, ator internacional é considerado “o agente que participa das relações internacionais, desempenha o próprio ato internacional, atua na dimensão dinâmica da sociedade internacional"17. Os atores internacionais podem ser ainda entendidos como uma "unidade do sistema internacional [...] que tem habilidade para mobilizar recursos que lhe permitem alcançar seus objetivos e capacidade para exercer influência sobre outros atores" 18 .

A caracterização dos atores internacionais constitui uma tarefa árdua em razão da multiplicidade de seres existentes. Essa dificuldade de caracterização advém, conforme entende Marcel Merle, de "uma confusão entre a noção de ator e a noção de papel cumprido; todos os atores potenciais não são forçosamente atores reais e todos os atores reais não cumprem necessariamente o mesmo papel"19.

A existência de uma multiplicidade de atores internacionais cria uma diversidade de funções na sociedade internacional contemporânea. Igualmente, muitos dos atores internacionais tornam-se voláteis, na medida em que emergem no cenário internacional e protagonizam em determinado período de tempo, e não mais depois, com atuação episódica. Isso ocorre diante da velocidade dos fluxos internacionais e das constantes transformações que se manifestam na arena internacional, especialmente decorrentes dos avanços tecnológicos.

Acerca da tipologia dos atores internacionais, é imprescindível destacar a concepção tradicional estudada por Marcel Merle ${ }^{20}$, que os apresenta com base em três tipos distintos: os Estados, que figuram como os principais atores internacionais cuja característica predominante é o estatocentrismo, assim como o poder de decisão e força de coerção dos quais são detentores; as Organizações Internacionais, que são organizações criadas pelos Estados, dotadas de autonomia e independência para desempenhar papéis específicos no cenário internacional; e, por fim, as forças transnacionais, que se manifestam na arena internacional a partir da

\footnotetext{
17 OLIVEIRA, Odete Maria de. Relações internacionais, direito e atores não estatais: delineamentos de fundamentação. In: OLIVEIRA, Odete Maria de. (Org.). Relações internacionais, direito e poder: cenários e protagonismos dos atores não estatais. Vol. I. Ijuí: Unijuí, 2014. p. 97.

18 BARBÉ, Esther. Relaciones Internacionales. Madrid: Tecnos, 1995. p. 117.

${ }^{19}$ MERLE, Marcel. Sociologia das relações internacionais. Tradução de Yvonne Jean. Brasília: Unb, 1981. p. 213.

${ }^{20}$ Ibidem. p. 132.
} 
intensificação da comunicação em rede. Gilberto Dupas $^{21}$, por sua vez, apresenta os atores internacionais agrupados de modo esquemático em três áreas principais: a) área do capital, que abrange os atores internacionais protagonistas da economia global, como corporações, sistema financeiro, associações empresariais, acionistas; b) área da sociedade civil, que compreende os indivíduos e organizações não governamentais; e c) área do Estado, onde protagonizam o próprio Estado, partidos políticos e instituições internacionais, por exemplo.

Entretanto, autores contemporâneos enfatizam uma classificação eclética dos atores internacionais, dividida em três modalidades: atores tradicionais, novos atores e atores emergentes. Nos atores tradicionais, estão incluídos os Estados e todas as suas derivações estatocêntricas. No grupo dos novos atores, estão inseridas as organizações internacionais, organizações não governamentais e empresas transnacionais, que são atores que exercem um interessante protagonismo presente em cenários singulares do âmbito internacional. No grupo dos atores emergentes, estão os considerados novos atores das relações internacionais, pelas mais variadas atividades e papéis exercidos em múltiplos espaços, como, por exemplo, os movimentos sociais, governos não centrais, partidos políticos, sindicatos, o crime organizado, o terrorismo e até eventualmente o próprio indivíduo ${ }^{22}$.

Em que pese a existência de uma multiplicidade de atores internacionais - estatais ou não estatais -, o presente artigo dedica atenção para as corporações transnacionais enquanto atores internacionais não estatais. As corporações transnacionais adquiriram maior relevância em especial depois do fim da Segunda Guerra Mundial. Isso não significa, porém, que antes desse marco histórico esses atores internacionais não existissem, porque os primeiros indícios do processo de constituição das corporações transnacionais estão na Europa e se referiam aos setores mais destacados da economia do século XIX, isto é, ao setor de carvão, aço, produção de alimentos e indústria farmacêutica ${ }^{23}$.

Em razão da acentuação da produção em massa, dos avanços tecnológicos, e do aumento da velocidade de transmissão e da capacidade de armazenamento de dados, ocorreu uma profunda transformação no modelo de produção existente desde os primórdios da era

\footnotetext{
${ }^{21}$ DUPAS, Gilberto. Atores e poderes na nova ordem global: assimetrias, instabilidade e imperativos de legitimação. São Paulo: UNESP, 2005. p. 27.

${ }^{22}$ OLIVEIRA, Odete Maria de. Relações internacionais, direito e atores não estatais: delineamentos de fundamentação. In: OLIVEIRA, Odete Maria de. (Org.). Relações internacionais, direito e poder: cenários e protagonismos dos atores não estatais. Vol. I. Ijuí: Unijuí, 2014. p. 102.

${ }^{23}$ BEDIN, Gilmar Antônio. A sociedade internacional e o século XXI: em busca da construção de uma ordem judicial justa e solidária. Ijuí: Unijuí, 2001. p. 309-310.
} 
capitalista. Com isso, intensificou-se a expansão dos mercados, tornando-se cada vez mais vulneráveis as atividades das corporações transnacionais ${ }^{24}$.

O surgimento e a expansão das corporações transnacionais, portanto, estão ligados com as transformações dinâmicas do modo de produção capitalista em razão da intensificação das atividades econômicas para além das fronteiras nacionais ${ }^{25}$. Com 0 fortalecimento das corporações transnacionais no pós-guerra, esses atores "passaram a constituir um fenômeno polêmico e de primeira ordem junto à sociedade internacional, convertendo-se ainda em desafios aos Estados"26.

Sobre a definição, Oliveira considera que a terminologia "empresa transnacional" abrange um conjunto de situações: estende-se para além das fronteiras nacionais; a estrutura da organização dessas empresas escapa do controle internacional; possui unidades em vários países; e é administrada por indivíduos de origens nacionais diversas, além de que suas decisões fogem da ótica nacional e suas operações não estão inseridas em nenhuma política nacional de determinado país ${ }^{27}$. Sua principal característica é a busca incessante por fins lucrativos sob uma racionalidade econômica puramente instrumental. Essa circunstância torna as corporações transnacionais os exemplos mais claros e intensos do desenvolvimento da economia capitalista no âmbito internacional. Constituem-se como "entidades de direito privado, vinculadas a uma ou mais ordens jurídicas nacionais"28.

O comércio praticado além dos territórios nacionais proporcionou a expansão das corporações transnacionais em nível global. Estas se submetem às legislações dos países em que iniciam as suas atividades e naqueles em que se estabelecem. Com isso, as empresas transnacionais aproveitam-se dessa multiplicidade de ordenamentos jurídicos dos Estados existentes na ordem internacional para se instalarem nos locais em que se apresentem maiores benéficos em todas as dimensões possíveis ${ }^{29}$. Na maximização de seus lucros, buscam sempre a melhor combinação possível de vantagens regulatórias, notadamente nos campos tributário, social e ambiental, na dispersão de suas unidades e etapas dos processos produtivos.

${ }^{24}$ CRETELLA NETO, José. Empresa transnacional e direito internacional: exame do tema à luz da globalização. Rio de Janeiro: Forense, 2006. p. 30.

${ }_{25}$ OLIVEIRA, Odete Maria de. Teorias globais e suas revoluções. Vol. III. Ijuí: Unijuí, 2005. p. 194-199.

${ }^{26}$ OLIVEIRA, Odete Maria de. Relações internacionais: estudos de introdução. 2. ed. Curitiba: Juruá, 2004. p. 246.

${ }^{27}$ Ibidem. p. 245.

${ }^{28}$ BEDIN, Gilmar Antônio. A sociedade internacional e o século XXI: em busca da construção de uma ordem judicial justa e solidária. Ijuí: Unijuí, 2001. p. 315-316.

${ }^{29}$ SALIBA, Graciane Rafisa. Convenções da OIT e empresas transnacionais: em busca da efetivação dos direitos trabalhistas. Rio de Janeiro: Lumen Juris, 2014. p. 75. 
As agendas das corporações transnacionais são instrumentos que permitem a centralização do aumento dos lucros, como forma de proteção das incertezas que o mercado oferece. Além disso, "surgem de uma combinação de competição de mercado, da demanda dos mercados financeiros e dos esforços dos indivíduos dentro delas para promover suas carreiras e aumentar seus ganhos" 30 .

Essas empresas diferenciam-se das empresas nacionais não apenas pelo seu campo de atuação transnacional, mas, ainda, pelo capital. 0 volume do capital imobilizado de uma corporação transnacional é extremamente elevado, o que demonstra um poder econômico colossal. A partir de tais conformações, as corporações transnacionais constituem atores fundamentais na sociedade internacional contemporânea e desempenham papéis de muita importância no que diz respeito ao poder político presente no cenário internacional ${ }^{31}$. Estudado o conceito de ator internacional, e, em especial, as corporações transnacionais no cenário internacional, passa-se a analisar o papel desses atores na efetividade do direito humano à alimentação.

\section{PAPEL DAS CORPORAÇÕES TRANSNACIONAIS NA (IN)EFETIVIDADE DO DIREITO HUMANO À ALIMENTAÇÃO}

Atualmente, as corporações transnacionais desempenham um papel central e decisivo junto ao funcionamento do sistema econômico internacional no que diz respeito ao setor produtivo, comercial e financeiro. Verifica-se, portanto, que as corporações transnacionais ocupam uma importante posição que, de certa forma, mostra-se bastante privilegiada enquanto um protagonista internacional detentor de significativo poder econômico ${ }^{32}$.

O fenômeno da globalização foi determinante para as transformações que ocorreram na sociedade internacional, onde, em termos econômicos, verificou-se uma grande interdependência econômica entre os Estados. A expansão e o fortalecimento da atuação das corporações transnacionais tornaram-se os principais desafios para garantir a proteção dos direitos humanos nos mais diversos Estados. De fato, as corporações transnacionais exercem

\footnotetext{
${ }^{30}$ KORTEN, David C. Quando as corporações regem o mundo. Tradução de Anna Terzi Giova. São Paulo: Futura, 1996. p. 69.

${ }^{31}$ OLSSON, Giovanni. Poder político e sociedade internacional contemporânea: governança global com e sem governo e seus desafios e possibilidades. Ijuí: Unijuí, 2007. p. 325-327.

32 OLIVEIRA, Odete Maria de. Relações internacionais: estudos de introdução. 2. ed. Curitiba: Juruá, 2004. p. 254.
} 
influência e possuem a capacidade de pressionar os Estados a ponto de ameaçar as garantias e os direitos conquistados através de longas batalhas sociais ${ }^{33}$.

As corporações transnacionais desempenham a função de produzir bens e serviços numa dimensão geográfica ampla e possuem alcance mundial. A partir de tal atividade, atingem seus objetivos primordiais: a maximização do lucro e a minimização dos custos. A obtenção do máximo de benefícios constitui um propósito a ser alcançado pelas corporações transnacionais. Para isso, essas entidades utilizam-se plenamente do poder econômico e de barganha das quais são detentoras, independentemente de circunstâncias e consequências que possam vir a resultar no espaço global ${ }^{34}$.

A atuação das corporações transnacionais no cenário internacional apresenta fatores positivos e negativos que são elencados por Barbé ${ }^{35}$. Nessa linha, alguns dos fatores positivos considerados pela mencionada autora são: a) o aumento do volume do comércio mundial; b) favorecimento ao desenvolvimento tecnológico; c) transferência de tecnologia aos países em desenvolvimento; d) estímulo a relações pacíficas entre Estados que desejam preservar uma ordem que os ajude a produzir riqueza e comércio; e e) rompimento de barreiras nacionais para acelerar a globalização da economia.

Dentre os aspectos negativos das corporações transnacionais, estão: a) aumento das diferenças entre ricos e pobres; b) criação de um sistema de países devedores e de dependência financeira; c) monopólio da produção e controle da distribuição mundial; d) aumento do bemestar das elites do Terceiro Mundo às custas dos pobres; e e) fragilização das culturas tradicionais, criando uma cultura mundial dominada pelo consumismo.

Logo, pode-se dizer que o papel exercido pelas corporações transnacionais no cenário internacional não é totalmente recebido como positivo, uma vez que sua atuação está resultando inclusive na violação de direitos humanos pelas mais variadas formas. As acusações quanto à violação de direitos humanos por parte dessas empresas não se referem somente às práticas empresariais em si, mas "envolvem tolerância, financiamento e facilitação para a

\footnotetext{
${ }^{33}$ SALIBA, Graciane Rafisa. Convenções da OIT e empresas transnacionais: em busca da efetivação dos direitos trabalhistas. Rio de Janeiro: Lumen Juris, 2014. p. 7.

${ }^{34}$ BEDIN, Gilmar Antônio. A sociedade internacional e o século XXI: em busca da construção de uma ordem judicial justa e solidária. Ijuí: Unijuí, 2001. p. 316-317.

${ }^{35}$ BARBÉ, Esther. Relaciones Internacionales. Madrid: Tecnos, 1995. p. 196.
} 
prática dos abusos de direitos humanos, o que, recentemente, vem sendo uma importante matéria considerada pela mídia e pelo interesse público"36.

Diante de tal premissa e com ênfase no direito humano à alimentação, cumpre notar que a atuação das corporações transnacionais pode influenciar na (in)efetividade desse direito. Como visto, o direito humano à alimentação abrange não somente a garantia do alimento ao indivíduo, mas, por igual, a garantia de uma alimentação balanceada, saudável e de qualidade. Além disso, o direito humano à alimentação engloba a luta contra a fome, para garantir que todos os indivíduos tenham acesso diário a alimentos em qualidade e quantidades suficientes para atender as necessidades vitais básicas essenciais para a manutenção da saúde ${ }^{37}$.

As corporações transnacionais expandiram-se de tal forma pelo cenário internacional, que o próprio sistema alimentício e até mesmo a agricultura transformaram-se gradativamente em estruturas produtivas voltadas precipuamente às finalidades almejadas por esses grandes atores internacionais. Atualmente, o sistema alimentício e a agricultura estão projetados para gerar lucros em favor de corporações transnacionais que atuam sem qualquer prioridade à satisfação das necessidades humanas, e mesmo com a comercialização de produtos químicos e agroindustriais potencialmente nocivos à saúde humana e ao meio ambiente ${ }^{38}$.

No tocante à configuração do sistema econômico apenas em proveito do lucro das corporações, há evidentes prejuízos à sociedade civil. Observe-se que, quando a produção de ração para os animais torna-se mais lucrativa para as corporações do que a comercialização de grãos para consumo humano, as corporações não hesitam em transformar produtos básicos, como milho e soja, por exemplo, em derivados para tratar as criações de suínos e aves.

Isso se comprova, por exemplo, pelos dados fornecidos pelo sexto inquérito da Global Feed Tonnage Survey de Alltech, em 2016, que relatam que a produção mundial de rações excedeu a fronteira de um bilhão de toneladas métricas de ração, ao ponto que o valor da indústria da alimentação animal através da fabricação de ração subiu para 460 milhões de dólares ${ }^{39}$.

\footnotetext{
${ }^{36}$ SALIBA, Graciane Rafisa. Convenções da OIT e empresas transnacionais: em busca da efetivação dos direitos trabalhistas. Rio de Janeiro: Lumen Juris, 2014. p. 88.

37 VALENTE, Flavio Luiz Schieck. Do combate à fome à segurança alimentar e nutricional: o direito à alimentação adequada. In: VALENTE, Flavio Luiz Schieck (Org.). Direito humano à alimentação: desafios e conquistas. São Paulo: Cortez, 2002. p. 37.

${ }^{38}$ KORTEN, David C. Quando as corporações regem o mundo. Tradução de Anna Terzi Giova. São Paulo: Futura, 1996. p. 325.

${ }^{39}$ GLOBAL feed production surpasses 1 billion metric tons for first time, with fewer feed mills. Alltech. 2017. Disponível em: http://go.alltech.com/alltech-feed-survey. Acesso em: 14 abr. 2017.
} 
Em outro exemplo, um documentário produzido pelo Museu de Ciências de Minnesota, nos Estados Unidos, aborda a questão do aumento populacional mundial e da alimentação humana, questionando a produção de alimentos ou ração animal. 0 documentário denominado “Dois bilhões a mais vem para jantar" aponta que grande parte das terras cultiváveis no mundo são usadas para produzir ração para animais e não para a alimentação humana. Isso resulta da disseminação das corporações transnacionais em nível global, espalhadas pelos mais diversos países, as quais preferem dedicar-se à produção da ração animal por ser mais lucrativa. De acordo com o mencionado documentário, no caso da criação de gado, por exemplo, são necessários cerca de treze quilos de ração para produzir meio quilo de carne. Isso indica que, quanto maior for a procura mundial por carne pela população, maior será o cultivo de ração para animais, e, consequentemente, maior será o lucro almejado pelas corporações transnacionais, assim como proporcionalmente menor será a produção de grãos para a alimentação humana ${ }^{40}$. Em outras palavras, pode sobrar carne de gado para pessoas de alto poder aquisitivo, mas faltarão (ou serão excessivamente onerosos) grãos para a alimentação do restante da população mundial.

No mesmo sentido, a Organização das Nações Unidas para a Agricultura e Alimentação (FAO), preocupada com o aumento populacional dos próximos anos, emitiu relatório concluindo que o mundo terá de produzir $70 \%$ mais alimentos até o ano de 2050 . No mesmo período, a produção mundial de carne deverá crescer mais de duzentos milhões de toneladas para atender a demanda projetada para a alimentação humana ${ }^{41}$.

Isso indica que, na medida em que para as corporações transnacionais é mais vantajoso fabricar ração animal, e considerando a premissa citada sobre a demanda de grãos para ração, há um sério risco de que crescente parcela da população global passe fome.

Para as corporações, fatos como a decorrente elevação dos custos da cesta básica e a incapacidade de aquisição e consumo por populações carentes passam a ser atribuídos a um mero problema econômico da equação entre oferta e demanda, a despeito de que isso causa fome, subnutrição ou até a morte. Isso, na sua ótica, seria uma injunção do "mercado", esse ente abstrato e etéreo que decidiria pela "mão invisível" os destinos da humanidade. Entretanto, o direito humano básico à alimentação restaria diretamente violado pela estrutura

\footnotetext{
${ }^{40}$ VIEIRA, Paulo André. A produção de alimentos vista do espaço. O Eco, 22 jul. 2013. Disponível em: http://www.oeco.org.br/blogs/geonoticias/27400-a-producao-de-alimentos-vista-do-espaco/. Acesso em: 14 abr. 2017.

${ }^{41}$ FAO participa de fórum na semana da alimentação. Organização das Nações Unidas para a Agricultura e Alimentação. Disponível em: http://www.fao.org.br/FAOpFSA.asp. Acesso em: 14 abr. 2017.
} 
econômica instalada e a atuação decisiva das corporações transnacionais do setor agroindustrial como seus atores principais.

No tocante à qualidade duvidosa dos alimentos pela utilização de agrotóxicos, também há vários exemplos, como o caso da Monsanto, uma importante corporação transnacional do segmento da alimentação. Apesar de a Monsanto anunciar que sua missão é contribuir no aumento da produção de alimentos de forma sustentável, não é exatamente isso que segmentos da sociedade civil vêm observando e denunciando. É o caso, por exemplo, do documentário “O mundo segundo a Monsanto", trabalho realizado pela jornalista Marie-Monique Robin, que demonstra como a Monsanto maquiou informações e manipulou resultados para fazer com que alimentos transgênicos fossem consumidos e comercializados no mercado global sem que houvesse qualquer pesquisa aprofundada sobre seus efeitos ao organismo humano. Esse documentário demonstra exatamente os efeitos disso na vida humana, abordando casos de indivíduos que foram afetados por esses alimentos por conta dos produtos químicos utilizados na sua composição ${ }^{42}$.

A companhia atua no ramo de insumos agrícolas, tendo reconfigurado o mercado mundial de sementes e agrotóxicos, atingindo com muito êxito a finalidade primordial de uma corporação transnacional: o aumento da lucratividade. De acordo com dados extraídos do Conselho Nacional de Segurança Alimentar e Nutricional, “o uso de agrotóxicos é uma das mais graves e persistentes violações do direito humano à alimentação [...] porque impede o acesso da população a alimentos livres de veneno e saudáveis"43. A atuação da Monsanto no cenário internacional, pela atividade normalmente desempenhada, viola diretamente o direito humano à alimentação, uma vez que o comércio de agrotóxicos contribui para o desenvolvimento de complicações de saúde através da alimentação humana.

Ressalta-se que a saúde humana é impactada pela ação dos agrotóxicos tanto de forma direta como indireta. De forma direta, um indivíduo pode ser afetado por um agrotóxico quando ingere uma carne ou vegetal que ocasiona dano à sua saúde, enquanto que, de forma indireta, o ser humano pode ser afetado "quando ocorre a manipulação errada do agrotóxico pelas pessoas

\footnotetext{
${ }^{42}$ ROBIN, Marie-Monique. O Mundo Segundo a Monsanto. Produção de Marie-Monique Robin. França, 2008. Disponível em: https://www.youtube.com/watch?v=J22coHHotpw. Acesso em: 14 abr. 2017.

43 OLIVEIRA, Cida de. Fusão entre Bayer e Monsanto deve agravar insegurança alimentar no Brasil, diz professor. Rede Brasil Atual, São Paulo, 18 set. 2016. Disponível em: http://www.redebrasilatual.com.br/ambiente/2016/09/fusao-entre-bayer-e-monsanto-vai-aumentarlucros-com-agrotoxicos-e-transgenicos-2129.html. Acesso em: 25 out. 2016.
} 
envolvidas nos processos de produção, utilização e colheita dos resíduos" ou, ainda, "quando o agrotóxico utilizado se dispersa para outro ambiente como um rio, lago ou lençol freático" 44 .

Logo, a posição e a imagem dessa corporação enquanto produtora mostram-se negativas quando relacionadas com a garantia e a efetividade do direito humano à alimentação. Conforme destaca Valente ${ }^{45}$, o número de mortes de crianças e idosos aumenta em razão do consumo de alimentos contaminados diariamente.

A atuação dessa específica corporação faz com que se intensifique a utilização de agrotóxicos nos alimentos, dificultando o acesso dos indivíduos a alimentos seguros e saudáveis. $\mathrm{Na}$ medida em que o ser humano ingere um alimento contaminado, fica exposto ao risco de desenvolver uma série de complicações à saúde, como, por exemplo, “diversos tipos de câncer, distúrbios endocrinológicos, neurológicos e mentais, além de mais chances de malformação congênita, distúrbios endócrinos, neurológicos e mentais" ${ }^{46}$.

Desta forma, é possível considerar que essa, como outras corporações transnacionais do segmento alimentício, contribui diretamente para moldar o sistema rumo a uma produção lucrativa em massa, a despeito de seus impactos sociais, ambientais e particularmente no espaço dos direitos humanos. Ademais, o custo dos produtos alimentícios "é composto por solos e lenços freáticos esgotados, contaminação da água com despejos de produtos químicos e afastamento de pequenas agriculturas familiares". E, assim, a maioria dos alimentos ofertados pelo atual sistema de produção alimentícia são processados em embalagens desperdiçadas em vão, com valores nutritivos duvidosos e contaminados por produtos químicos ${ }^{47}$. Nessa linha, a contaminação ambiental derivada dessa prática comercial que garante lucros privados nada mais é do que a externalização dos seus custos, ônus e riscos para a sociedade em geral e o poder público.

Embora os supermercados estejam fartamente abastecidos, o sistema visa à maximização do lucro como um fim primordial, e, para isso, adotam-se medidas inadequadas

\footnotetext{
${ }^{44}$ GODEFROID, Rodrigo Santiago. Metodologia do ensino de biologia e química: o ensino de biologia e o cotidiano. Curitiba: IBPEX, 2010. p. 51.

${ }^{45}$ VALENTE, Flavio Luiz Schieck. Do combate à fome à segurança alimentar e nutricional: o direito à alimentação adequada. In: VALENTE, Flavio Luiz Schieck. (Org.). Direito humano à alimentação: desafios e conquistas. São Paulo: Cortez, 2002. p. 38.

${ }^{46}$ OLIVEIRA, Cida de. Fusão entre Bayer e Monsanto deve agravar insegurança alimentar no Brasil, diz professor. Rede Brasil Atual, São Paulo, 18 set. 2016. Disponível em: http://www.redebrasilatual.com.br/ambiente/2016/09/fusao-entre-bayer-e-monsanto-vai-aumentarlucros-com-agrotoxicos-e-transgenicos-2129.html. Acesso em: 25 out. 2016.

${ }^{47}$ KORTEN, David C. Quando as corporações regem o mundo. Tradução de Anna Terzi Giova. São Paulo: Futura, 1996. p. 325.
} 
que refletem diretamente na vida do ser humano. Há denúncias de declarações nutritivas enganosas, omissão de dados sobre aditivos, hormônios sintéticos e resíduos tóxicos que o indivíduo possa estar ingerindo, e oferta de pouquíssimas opções de escolha de alimentos $\operatorname{orgânicos~e~não~processados~}^{48}$. Logo, o direito humano à alimentação tem sido constantemente violado por uma estrutura produtiva voltada primordialmente apenas para aquilo que as corporações transnacionais do setor considerem mais lucrativo fazer.

Como outro exemplo, pode-se referir a Nestlé, que, até então, declarava a ausência de qualquer derivado de transgênicos em seus produtos, e vem sendo alvo de denúncias pela constatação de organismos geneticamente modificados, sem que tal informação esteja declarada nas embalagens. Dentre as denúncias realizadas pelo Greenpeace ${ }^{49}$, os testes confirmaram a existência de soja transgênica da Monsanto em pelo menos um dos produtos fabricados pela Nestlé. Da mesma forma, a Kellogg's, fabricante de cereais, também foi alvo de denúncias quando pesquisas revelaram que o milho e a soja utilizados nos cereais eram transgênicos. Além de uma afronta aos direitos do consumidor, por não informar adequadamente a composição e origem de suas matérias-primas, trata-se de uma verdadeira violação ao direito humano à alimentação, quando milhares de pessoas lutam contra a utilização de transgênicos em razão dos potenciais efeitos nocivos à saúde humana ${ }^{50}$. Essas práticas baseadas na forte utilização de insumos químicos adotadas pelas corporações transnacionais do setor alimentício têm resultado em agravos à saúde humana, consubstanciados no aumento do desenvolvimento de doenças crônico-degenerativas ${ }^{51}$.

Verifica-se, portanto, que as corporações transnacionais não são atores internacionais com propósitos morais e sociais, mas unicamente econômicos. Enquanto a proliferação das corporações transnacionais ocorrer no espaço global com esse único propósito, o direito humano à alimentação continuará a ser objeto de violação. Nesse ponto, pode ser retomado o argumento central de Galtung, no sentido de que a desconexão entre as necessidades humanas e os direitos

\footnotetext{
${ }^{48}$ KORTEN, David C. Quando as corporações regem o mundo. Tradução de Anna Terzi Giova. São Paulo: Futura, 1996. p. 325.

${ }^{49}$ GREENPEACE denuncia: produto da Nestlé contém transgênicos. Greenpeace, 31 mar. 2003. Disponível em: http://www.greenpeace.org/brasil/pt/Noticias/greenpeace-denuncia-produto-d/. Acesso em: 25 out. 2016.

${ }^{50}$ CEREAIS Kellogg's: dose dupla de transgênicos, pesticidas e antibióticos em seus produtos. Notícias Naturais, 10 nov. 2014. Disponível em: http://www.noticiasnaturais.com/2014/11/cereais-kelloggs-dosedupla-de-transgenicos-pesticidas-e-antibioticos-em-seus-produtos/\#ixzz40KrBgg22. Acesso em: 25 out. 2016.

51 VALENTE, Flavio Luiz Schieck. Do combate à fome à segurança alimentar e nutricional: o direito à alimentação adequada. In: VALENTE, Flavio Luiz Schieck (Org.). Direito humano à alimentação: desafios e conquistas. São Paulo: Cortez, 2002. p. 39.
} 
humanos constitui um elemento decisivo para a inefetividade de vários destes, uma vez que, em diversas situações, apenas a mudança da estrutura econômica (e, no caso do direito humano à alimentação, a mudança da estrutura produtiva) poderá permitir sua plena efetivação na sociedade contemporânea ${ }^{52}$.

Desta forma, para que o direito humano à alimentação seja efetivamente garantido, é necessária uma transformação no sistema alimentício e também agropecuário, de feições mais locais ou regionais e com produtos mais saudáveis. Korten ${ }^{53}$ entende que a adoção de tais medidas certamente proporcionará a efetividade do direito humano à alimentação, resultando, assim, em terra fértil, alimentos não contaminados e consequentemente pessoas sadias e seguras. É necessária, portanto, uma reestruturação do sistema de acordo com os interesses da sociedade na prevalência dos seus inalienáveis direitos humanos e não os das corporações transnacionais.

\section{CONCLUSÃO}

As corporações transnacionais são consideradas importantes atores internacionais não estatais e que exercem influência significativa na atual sociedade internacional contemporânea. Sua principal característica é a busca incessante pela maximização do lucro com a minimização dos custos, de modo que possuem propósitos exclusivamente econômicos.

Verificou-se que as corporações transnacionais constituem exemplos claros do desenvolvimento da economia capitalista no âmbito internacional, e vem crescendo gradativamente em tamanho e poder. As corporações transnacionais diferenciam-se das empresas nacionais pelo seu campo de atuação transnacional e especialmente pelo volume do capital imobilizado altamente elevado e dispersão geográfica fluida e dinâmica.

Apesar dos grandes avanços na economia mundial, o papel desempenhado pelas corporações transnacionais no atual cenário internacional não é totalmente concebido como positivo, tendo em vista que muitas atividades exercidas por elas resultam em abuso a direitos básicos da pessoa humana.

\footnotetext{
52 GALTUNG, Johan. Direitos humanos: uma nova perspectiva. Tradução de Margarida Fernandes. Lisboa: Instituto Piaget, 1994. p. 107-108.

${ }^{53}$ KORTEN, David C. Quando as corporações regem o mundo. Tradução de Anna Terzi Giova. São Paulo: Futura, 1996. p. 326-327.
} 
A atuação das corporações transnacionais, em especial, reflete diretamente no direito humano à alimentação. Além de um direito básico e inerente à pessoa humana, a alimentação configura uma necessidade relacionada diretamente com a sobrevivência do homem. Esse direito abrange a garantia do alimento diário ao indivíduo, assim como uma alimentação balanceada, saudável e de qualidade.

Entretanto, com a expansão das corporações transnacionais em nível global, atualmente vigora um sistema alimentício mundial estruturado para a geração de lucros em favor das corporações transnacionais. Práticas corporativas da Monsanto, Nestlé e Kellogg's, por exemplo, referenciais no setor alimentício, demonstram como a alimentação humana pode ser afetada pelas atividades das corporações transnacionais.

Um impacto das corporações no direito humano à alimentação reside no seu protagonismo na estrutura produtiva que privilegia exclusivamente os seus lucros e não a satisfação da segurança alimentar da sociedade, permitindo, por exemplo, a direta conversão de alimentos humanos básicos em ração animal simplesmente pela sua maior lucratividade.

Por sua vez, a utilização de agrotóxicos e transgênicos constitui outra causa refletiva dessas atividades ao direito humano à alimentação, uma vez que a utilização de produtos químicos e agroindustriais nos alimentos é nociva à saúde humana, aumentando os riscos de desenvolvimento de patologias de várias naturezas e sem a devida informação aos consumidores.

Assim, verifica-se que o direito humano à alimentação não é absolutamente efetivado. Para que essa realidade seja transformada, faz-se necessária uma reconfiguração no sistema alimentício e agropecuário, substituindo essas práticas nocivas realizadas pelas corporações transnacionais por sistemas alimentares agrícolas mais saudáveis. Por fim, é necessário estudar essa incitante realidade, na busca pela efetivação do direito humano à alimentação e pela garantia da dignidade da pessoa humana, recompondo a essencial conexão entre a efetivação dos direitos humanos e a satisfação das necessidades humanas que lhes são subjacentes.

\section{REFERÊNCIAS}

BARBÉ, Esther. Relaciones Internacionales. Madrid: Tecnos, 1995.

BEDIN, Gilmar Antônio. A sociedade internacional e o século XXI: em busca da construção de uma ordem judicial justa e solidária. Ijuí: Unijuí, 2001.

BOBBIO, Norberto. A era dos direitos. Rio de Janeiro: Campus, 1992. 
CEREAIS Kellogg's: dose dupla de transgênicos, pesticidas e antibióticos em seus produtos. Notícias Naturais, 10 nov. 2014. Disponível em:

http://www.noticiasnaturais.com/2014/11/cereais-kelloggs-dose-dupla-de-transgenicospesticidas-e-antibioticos-em-seus-produtos/\#ixzz4OKrBgg22. Acesso em: 25 out. 2016.

CRETELLA NETO, José. Empresa transnacional e direito internacional: exame do tema à luz da globalização. Rio de Janeiro: Forense, 2006.

DUPAS, Gilberto. Atores e poderes na nova ordem global: assimetrias, instabilidade e imperativos de legitimação. São Paulo: UNESP, 2005.

FAO participa de fórum na semana da alimentação. Organização das Nações Unidas para a Agricultura e Alimentação. Disponível em: http://www.fao.org.br/FAOpFSA.asp. Acesso em: 14 abr. 2017.

GALTUNG, Johan. Direitos humanos: uma nova perspectiva. Tradução de Margarida Fernandes. Lisboa: Instituto Piaget, 1994.

GLOBAL feed production surpasses 1 billion metric tons for first time, with fewer feed mills. Alltech. 2017. Disponível em: http://go.alltech.com/alltech-feed-survey. Acesso em: 14 abr. 2017.

GODEFROID, Rodrigo Santiago. Metodologia do ensino de biologia e química: o ensino de biologia e o cotidiano. Curitiba: IBPEX, 2010.

GREENPEACE denuncia: produto da Nestlé contém transgênicos. Greenpeace, 31 mar. 2003. Disponível em: http://www.greenpeace.org/brasil/pt/Noticias/greenpeace-denuncia-produtod/. Acesso em: 25 out. 2016.

HUNT, Lynn. A invenção dos direitos humanos: uma história. Tradução de Rosaura Eichenberg. São Paulo: Companhia das Letras, 2009.

KORTEN, David C. Quando as corporações regem o mundo. Tradução de Anna Terzi Giova. São Paulo: Futura, 1996.

MERLE, Marcel. Sociologia das relações internacionais. Tradução de Yvonne Jean. Brasília: Unb, 1981.

OLIVEIRA, Cida de. Fusão entre Bayer e Monsanto deve agravar insegurança alimentar no Brasil, diz professor. Rede Brasil Atual, São Paulo, 18 set. 2016. Disponível em:

http://www.redebrasilatual.com.br/ambiente/2016/09/fusao-entre-bayer-e-monsanto-vaiaumentar-lucros-com-agrotoxicos-e-transgenicos-2129.html. Acesso em: 25 out. 2016.

OLIVEIRA, Odete Maria de. Relações internacionais, direito e atores não estatais: delineamentos de fundamentação. In: OLIVEIRA, Odete Maria de. (Org.). Relações internacionais, direito e poder: cenários e protagonismos dos atores não estatais. Vol. I. Ijuí: Unijuí, 2014, p. 33-131.

OLIVEIRA, Odete Maria de. Relações internacionais: estudos de introdução. 2. ed. Curitiba: Juruá, 2004. 
OLIVEIRA, Odete Maria de. Teorias globais e suas revoluções. Vol. III. Ijuí: Unijuí, 2005.

OLSSON, Giovanni. Poder político e sociedade internacional contemporânea: governança global com e sem governo e seus desafios e possibilidades. Ijuí: Unijuí, 2007.

PÉREZ LUÑO, Antonio Enrique. Derechos humanos, estado de derecho y constitución. 4. ed. Madrid: Tecnos, 1991.

PIOVESAN, Flávia. Temas de direitos humanos. 5. ed. São Paulo: Saraiva, 2012.

PRONER, Carol. Os direitos humanos e seus paradoxos: análise do sistema americano de proteção. Porto Alegre: Sergio Antonio Fabris, 2002.

ROBIN, Marie-Monique. O Mundo Segundo a Monsanto. Produção de Marie-Monique Robin. França, 2008. Disponível em: https: / /www.youtube.com/watch?v=J22coHHotpw. Acesso em: 14 abr. 2017.

SALIBA, Graciane Rafisa. Convenções da OIT e empresas transnacionais: em busca da efetivação dos direitos trabalhistas. Rio de Janeiro: Lumen Juris, 2014.

VALENTE, Flavio Luiz Schieck. Introdução. In: VALENTE, Flavio Luiz Schieck (Org.). Direito humano à alimentação: desafios e conquistas. São Paulo: Cortez, 2002.

VALENTE, Flavio Luiz Schieck. Do combate à fome à segurança alimentar e nutricional: o direito à alimentação adequada. In: VALENTE, Flavio Luiz Schieck (Org.). Direito humano à alimentação: desafios e conquistas. São Paulo: Cortez, 2002, p.37-70.

VIEIRA, Paulo André. A produção de alimentos vista do espaço. O Eco, 22 jul. 2013. Disponível em: http: // www.oeco.org.br/blogs/geonoticias/27400-a-producao-de-alimentos-vista-doespaco/. Acesso em: 14 abr. 2017.

Recebido em: 15/04/2017 / Revisões requeridas em: 13/06/2017 / Aprovado em: 26/06/2017

\section{COMO CITAR O ARTIGO (ABNT)}

LAZARETTI, Isadora Kauana; OLSSON, Giovani. O PAPEL DAS CORPORAÇÕES TRANSNACIONAIS NO DIREITO HUMANO À ALIMENTAÇÃO. Revista Eletrônica do Curso de Direito da UFSM, Santa Maria, RS, v. 12, n. 2, p. 572-592, ago. 2017. ISSN 19813694. Disponível em: <https://periodicos.ufsm.br/revistadireito/article/view/26698>. Acesso em: dia mês. ano. doi:http://dx.doi.org/10.5902/1981369426698. 